\title{
$7 \quad$ Women and Families in Transition
}

Part III explores a pivotal transitional period for Matsu. As the army left and the islands gradually opened up to the world, both individuals and the island society faced a new situation. Chapter 7 follows the women of Matsu and the struggles they faced-between marriage and self, family and work, Matsu and Taiwan - through the late military period into the present day.

In Chapter 3, I discussed the changes that women experienced from the fishing period into the era of military rule. When fishing was the main source of household income, men were valued more highly than women, who had very few opportunities to receive formal education. Although elementary schools, and later some middle schools, were built across the islands under the WZA, most women who finished primary school promptly began to conduct G. I. Joe business to earn money for their parents' families. After marriage, their earnings went towards supporting their husbands' families. Although women's ability to engage in petty commerce and to contribute economically raised their status both at home and in the larger society (as shown in Chapter 4), their lives continued to revolve closely around the family. As a Matsu saying goes: "When the mother is there, the family is complete; when the mother isn't there, the family falls apart" (F. noeyng ne duoli, suo tshuo iengnongnong. noeyng ne namo, tshuo tsiu sang lo). A woman was the protector of her family, supporting its very existence, and sacrificing herself for it.

During the late military period, however, some women began to take their lives in different directions. Although women of this period were not afforded the advantages that men had access to, such as receiving government-guaranteed education in Taiwan, many of them left for 
Taiwan in search of jobs to support their families financially. Others went to Taiwan to study, if their families allowed it. Their experiences in Taiwan had a huge impact on their later lives. This chapter examines the new struggles that women confronted. I take three women, born between 1950 and 1980, who lived through the era of military rule and beyond, to discuss the rise of a new female self and the changing meanings of contemporary family and marriage. Rather than representing Matsu women in general, their unique experiences provide crucial insight into the changes in women's conceptions of themselves and the challenges that contemporary Matsu society faces today.

\section{Rising from Floriculture}

Xiaofen is one of the most elegant women in Matsu. Her clothing always exhibits a unique style, and she has meticulously turned the first floor of her home into a café. Still, my most lasting impression of her is from 2008, during a pilgrimage to China. She planned it as a reunion for her siblings' families. The line of several dozen people in a pilgrimage procession was quite an eyecatching sight.

Cao Xiaofen was born in 1956 and is the eldest of seven children. In order to help share the burden of supporting the family, soon after graduating from elementary school she began to work at a bookstore in Shanlong as an assistant. She says that she always loved to study, and even used the money she earned from her first job to go back to middle school for a semester, returning to work only when she ran out of money. At the impressionable age of eighteen, a matchmaker arranged for her to marry into the Chen family in Shanlong. At that time, her husband's family had opened a restaurant catering to the military, doing both G. I. Joe business and raising chickens at the same time. Xiaofen was expected to help with all of it, and that kept her extremely busy.

As G. I. Joe business became more and more competitive, the family had to find other ways of making ends meet. In 1976, Xiaofen's motherin-law arranged for her to leave Matsu for Taiwan, and so she arrived, pregnant, in the Bade district of Taiwan to work in the Lianfu Clothing Factory. At that time, means of communication and travel between Matsu and Taiwan were quite limited, and she had few chances to see her husband. He would occasionally come to visit her, and each time he 
prepared to leave again, she felt heartbroken and hoped that the ships between the Keelung harbor and Matsu would not set sail. Tragically, not long after her child was born, her husband fell ill with uremia. Since Matsu is fairly remote, and a lack of medical knowledge delayed his care even further, her husband had to spend many years on dialysis in Taiwan. When her husband got sick, Xiaofen left her work at the clothing factory and moved to Taipei to take care of him. Burdened by medical expenses, and with very little education and no professional training, she could only engage in manual labor to make money. In the winter she sold cakes in a market, and iced drinks in the summer at the hospital gates in order to supplement the family income. She says that one day after work she was pulling her cart home and heard someone behind her calling, "Mister, Mister!" and she realized with surprise that her skin had darkened from being out in the sun year round, and her appearance was indistinguishable from that of a man (J. Liu 2004c).

When her husband passed away in 1991, she finally had a moment to catch her breath, and she decided to take classes in floriculture. She said:

I had a chance to study flower arrangement, and it was like I was back in primary school and could remember how happy studying makes me!

After many years of toil, however, she was diagnosed with cancer in 2000. During her treatment, the illness and the suppression of her emotions over many years of caring for the family led to depression. She stopped working in the market for nearly half a year, and this period of rest gave her a chance to reconsider her own life. She realized that the tense relationship with her mother-in-law had caused her to become servile and obedient. Because she was forced to take care of her husband, mother-in-law, and child who were all frequently ill, she found herself suffering from low self-esteem and had gradually begun to cut ties with people. After her own illness, her siblings and elementary school classmates wanted her to come back to her childhood village, Ox Horn, to recover, so she moved in with one of her younger sisters. An old classmate, Cao Yixiong, was promoting "Village Conservation" (see Chapter 8) at that time. He often came to visit, providing emotional support by taking her on walks to show her how the village had been transformed and renewed. He encouraged her to develop her artistic 
talents and to move back to Matsu for good to open a flower shop and a café in a historic building in the village. With the support of friends, Xiaofen gradually returned to health, and she decided to go back to Taiwan to learn to become a barista before returning to Matsu to open a café. She did not imagine that her flower shop would eventually do brisk business, and that her classes in flower arranging would prove to be very popular. Today, she is often invited to other islands to give lessons at women's associations and community centers. She said: "Floriculture helped me find my 'self,' and it also made me realize that Matsu is the place I'll always come back to." With her new chance at life, she is not only a florist, but now also plays the role of the central figure of "eldest sister" in her family. She arranges family events at specific times over the year, which helps to solidify and maintain their familial relationships:

The place where I'm living now is the "family home" (niangjia) for my brothers and sisters. Each year, I organize a family reunion and we all go traveling together. My sisters and I also have a separate get-together, and it helps us all stay close.

When her florist's business does well and she makes some extra money, she sends it to her son in Taiwan.

Over the past little while, I've done a pretty good business, so I've sent NTD $\$ 500,000$ to my son and his wife in Taiwan. They have several children, so their financial situation is tight.

Xiaofen's case is particularly dramatic. After arriving in Taiwan, she suffered greatly from her illness, yet over the course of her sickness and recovery, she also managed to gradually free herself, slowly recognizing how severely she had been constrained by the traditional mother-in-law/ daughter-in-law relationship. A succession of family misfortunes caused her to withdraw even further, until eventually she was diagnosed with cancer and was confined to her own tiny world. Then, allowed the opportunity to study floriculture and to develop her talents, she was able to achieve a new selfhood. With the emotional support and practical aid of her family and former classmates in Matsu, she was able to recover from her illness, and now she has also established herself as the center of two different families. She not only serves as a bridge between her 
brothers and sisters, but also helps support the younger generation of her own family in Taiwan.

\section{Torn Between 0 and 9}

Xiufang loves to chat with us, but she only appears in the late evenings. Each time, she says: "I'm running around all day, and I can finally relax when I'm chatting with you." But she can't stay for too long, or her husband will call and urge her to come home.

Li Xiufang has a very busy job as an accountant. At 8 am each morning, she starts her day rushing back and forth between two different government agencies. She gets off at $6 \mathrm{pm}$ and must hurry to the hostel that her mother-in-law runs to help keep the accounts. After dinner, she frequently goes back to the office, finishing up at $10 \mathrm{pm}$. She has been working in Matsu for twenty-one years, and these long days happen at least once a week and more often three times a week. She is transferred to a new government agency every four years and has already held positions in twelve different agencies.

Although she is kept very busy, when Xiufang speaks of her work, she always has a smile and a look of pride on her face. With her circumspect manner and her natural aptitude for numbers, she is often able to help her colleagues deal with the most complicated write-offs. When she is able to handle some thorny numbers, she says she always feels "a great sense of accomplishment!" Still, her demanding work reduces the amount of time she can spend with her family, and she reveals a sense of regret about her children. I asked her why she had chosen to work as an accountant, and she told me:

Because my dad's family had no money, he didn't have the chance to continue his education. He felt like he'd really missed out, so he always placed a lot of importance on our education. When I graduated from middle school, my dad sent the whole family to Taiwan so we could study there. When I was small, my mother washed clothes, tailored uniforms for soldiers, sewed military insignias, sold seaweed, working herself to the bone to make money. When we went to Taiwan, she came along to look after us and sold dumplings to help support the family. When I got into a business college, my dad encouraged me to get a degree.

After graduation, Xiufang got a job as an accountant in a government office. She married a man from Matsu, returned there for work, and had 
two children. Her husband also works in a government organization, and they are typical of many families in Matsu in which both husband and wife work for the government and enjoy a very stable lifestyle. Her husband makes allowances for her busy job, which often prevents her from coming home on time. He is the one who makes dinner and looks after the children. Xiufang is responsible for all of the cleaning, and in this way, the two cooperate in the running of the household.

When Xiufang speaks of her family, she often emphasizes that she is able to give her children ample time and space in which they can focus on their studies. This relates to Xiufang's own difficult experiences going to school in Taiwan as a teenager. Moving from a remote island to a metropolis, Xiufang was packed into a small apartment with her five siblings as well as five cousins to study and sleep together. She says that at the time, she did not have her own desk or her own bed. When she got home from school, she would have to make dumplings until late at night, and because of this, she tried her best to stay at school to study until $9 \mathrm{pm}$ before returning home. Now, she is proud that she can offer her children their own personal space in which to grow up and develop.

Because of her hectic schedule, however, Xiufang has no time to cook for her children, and that is a source of deep regret for her. In Matsu, one very important traditional role that mothers play is to cook for the family. The meal that a mother prepares represents a maternal role that many Matsu people recall with deep emotion. Li Jinmei, who served for twenty-five years on the county legislature in Matsu County, says that during the time she was engaged in politics, she would come home each day at $5 \mathrm{pm}$ to cook for her family, and only after they had eaten together would she return to her meetings. Today, we find a vibrant scene of married working women returning to their mothers' houses to eat dinner. Xiufang's family also often goes over to her mother's house to eat dinner. From this we can also see that for women in Matsu today, although their sense of self is indissociable from their work, they still identify strongly with the traditional role of the mother as the center of the household. The emotional intimacy fostered by a mother cooking dinner for the family and bringing everyone together is still irreplaceable for Xiufang in terms of how she views herself as a woman. For this reason, although she considers her career and her professional capabilities to be significant 
accomplishments, she still feels guilty about not being able to come home to cook for her children every night. As a contemporary woman, she is torn between striving for professional success and fulfilling the traditional role of the mother.

\section{In Search of a Common Vision}

Every time Lihong goes out, she's always meticulously made up. Her hair smells sweet, because she always washes her hair before she meets with us. Her eyebrows are carefully plucked, and her face is rosy and full. She puts on eyecatching necklaces, bracelets, and other jewelry, and even when she's in a tracksuit, she always shows her own sense of style.

Chen Lihong was born in 1971, one of five siblings, the youngest of whom is a boy. She recounted:

I'm the second oldest in my family, and my older sister and I both got good grades. But we were not well-off, so she and I decided not to go on with our schooling after graduating from high school, and instead to help make some money for the family so our younger siblings would have an easier time of it.

I asked her what she and her sister did to help. She told me they did all kinds of jobs, but that she was especially good at "carrying water" (taishui), and that she would collect nearly all of the water that the family used. Back when Matsu did not have running water, the water used by a household would be collected from wells and carried back to the home. She said:

I could carry a lot of water! In elementary school, I used to go with my sister. Then in middle school I would do it alone, and I'd hurry back from school each day to help out. The first gift my dad ever gave me was a stainless-steel water pail specially ordered from Taiwan. It's still there in my parents' house.

We can readily sense Lihong's satisfaction about the help she was able to give her family. In fact, like Xiufang, Lihong could have gone to Taiwan to study after high school, but she decided to stay so that the money could go towards the education of her younger brother. Years later, on his wedding invitation, he specially thanked her and her older sister, "and when I saw that, all of it [the sacrifice] was worth it," she told me with tears in her eyes.

Although both Lihong and Xiaofen sacrificed themselves to help their families and in particular their younger siblings, the former is different 
from the latter in that she grew up during the late period of the WZA. Lihong's family engaged in many different kinds of G. I. Joe businesses, including selling breakfast foods and snacks, and running a karaoke bar. As a girl, she would keep watch over the karaoke bar as she studied, and so had contact with the military from a young age. She told me that early on the soldiers would fight over her affections, and not a few of them tried to ingratiate themselves with her. "Were you ever interested?" I asked her. "I can't say I never was," she responded. However, one of her aunts had married a soldier, and after she went with him when he was posted to Taiwan, their marriage suffered. Because of this, Lihong felt that it was safer to marry a man from Matsu, with whom she would have a greater chance of having a secure life and a harmonious marriage. Doing chores and helping out the family as a girl, she had already started to develop her own ideas about the future.

After she grew up, she chose a local Matsu man with a steady income from among her many admirers. Her husband worked for the government, and she was also employed by the government at the time on contract, so together the two of them had a healthy income. After they married, they soon bought a house and a car, and a year later had a baby. Just as their life together seemed to only be getting better, her husband took up gambling, and then began to have an affair. Lihong said:

When I found out that he'd been having an affair and I argued with him about it, he told me that I shouldn't poke my nose into what he did outside the home. He wanted me to be a traditional wife and stay at home. As long as I took care of the family, everything was fine.

Lihong could not accept her husband's attitudes, and once he had been unfaithful she allowed herself to become emotionally detached from their marriage. She worked even harder to make money, so that she could prove to the court that she had the economic means to take care of her son, hoping to be granted custody of him. She became licensed as a nurse's aid in order to get a better job with a steady salary. Still, since her husband could provide a better home environment, she agreed to allow her son to continue to live with him. She arranged a set time to come visit him and to take him out to do something fun. After her divorce, Lihong did not move back to her parents' house, as was traditionally expected of women, but instead rented a room, wanting her own private space in 
which to live. Each time we met, she would always be carefully dressed and made up. She felt that after her divorce, she needed to keep up her appearance, to make herself feel better than she had before. She told me: "Many women realize only after they get divorced that they have a lot of capabilities. The struggle for survival brings out latent potential."

Like many traditional women in Matsu, Lihong has sacrificed for her family since she was a young child. In the process, however, she has also slowly been developing herself: she planned out the kind of marriage and family that she wanted, and made it happen. Despite all of her careful planning, her marriage unfortunately ended in divorce, but she described the outcome this way:

My husband and I struggled for a long time to build the kind of family that we had. But as soon as we had everything we'd been working for so hard, we lost sight of a common goal for the future.

Lihong's reflections reveal that she did understand that her husband's leaving might also have been caused by his pursuit of "another kind of self [beyond the family]": it was precisely because husband and wife lost their common vision that their marriage failed and their home life collapsed. In any case, Lihong is no longer willing to submit to a man's demands, as women had done in the past. Her decisions demonstrate how different contemporary Matsu matrimony is from the traditional model. In the past, as long as men brought money home to support the family, they were free to gamble in their spare time; even affairs were tolerated by their wives. But Lihong and most of the other women in Matsu no longer want to be traditional wives. In other words, contemporary Matsu households can no longer successfully operate on the assumption of the self-sacrifice of one of the partners (most often women). Quite the opposite, creating a common vision that both partners, along with the entire family, can work toward together has become the foundation of contemporary marriages and families in Matsu.

\section{Conclusion: Struggling Women, Families, and the Future of the Islands}

The cases of Cao Xiaofen, Li Xiufang, and Chen Lihong clearly show that the women of Matsu did not have much chance to receive higher 
education during the military period. Most women ended their education after elementary or middle school, and immediately began engaging in small-scale commercial business to help support their families or to provide their siblings with more opportunities than they had been given themselves. After marriage, they were expected to take care of their husbands and their families, and also to raise children. Although, as Chapter 3 indicated, they did obtain a kind of free space and greater power than they had in the earlier fishing period, most of them still struggled to be loyal sisters and filial daughters-in-law (e.g. Lee 2004). Cao Xiaofen and Chen Lihong are clear examples: they both enjoyed school but were unable to continue their education because of family responsibilities. Despite her pregnancy, Cao Xiaofen had to obey her mother-in-law's dictates and move to Taiwan to work in a clothing factory, living separate from her husband. The family took precedence over the individual.

Nevertheless, the examples of Xiaofen, Xiufang, and Lihong also show how a new female self-consciousness, one that was distinct from the sociocultural self, developed between the military period and the contemporary era. For instance, Xiaofen is the eldest of the three and the most constrained by traditional culture, encountering shattering separation, deaths and illness throughout her life; however, these sufferings have prompted her to reflect on the ultimate causes. With the support and care of her siblings and friends in Matsu, she was able to regain a new life. She became a new subject, not only managing her successful flower business but also putting great effort into sustaining emotional ties between her siblings. She works hard to reach a balance between her business self and the sociocultural one (playing the kinship roles of mother and eldest sister).

Xiufang also had the opportunity to go to Taiwan when she was young. She was fortunate in that she received higher education there and so was able to get a stable job in the Matsu government when she returned. Becoming a successful accountant is clearly a point of great pride for her. She is also proud of the fact that she is able to provide a comfortable home environment for her children. Nonetheless, she is upset that she cannot play the role of a "proper" mother-who cooks and cares for the family, holding it all together. Whether in life or in work, she is torn 
between two extremes-between 0 and 9 , the traditional and the contemporary.

Lihong is very different, and from her situation we can see an intermediate stage between the traditional and the contemporary. Compared to Mahmood's (2005) depiction of the ethical formation of Egyptian women, Lihong's example presents an even better case of the burgeoning of a modern subjectivity. Lihong made the kinds of sacrifices that women in the traditional culture have long made, and she even took the decision not to study further so as to afford her younger siblings the opportunity to finish school. In the process, however, she began to develop her subjective consciousness, and formed plans for her own future and imagined what her life could be like. As a result, when her marriage began to flounder, she rejected a role of further self-sacrifice and refused to continue as the traditional wife. As she encountered myriad difficulties in the divorce process, her subjective consciousness became all the more engaged, and she pursued economic independence so as to gain custody of her son. Of course, after the dismantling of military rule Matsu society developed in myriad ways, and the new job options in Matsu have given Lihong more varied opportunities to develop her subjectivity. She can now make investments in her future, and actively seek out new employment so as to better herself and her situation.

Lihong's case underlines the fact that marriage and family in Matsu today differ significantly from the past. That is to say, in contemporary Matsu, women's self-awareness has come to the fore, and the continuation of a marriage and family depends on whether husband and wife are willing to negotiate and create a common vision for the family. In fact, this is true not only of marriages. In the Chapter 8 , we will see that Matsu as a whole - from villages to islands-faces a similar challenge: how to find a common sense of the future in the midst of these multitudinous new selves. 